\title{
Training in and comfort with diagnosis and management of ophthalmic emergencies among emergency medicine physicians in the United States
}

\author{
Joshua H. Uhr ${ }^{1}$ • Nicholas J. Governatori ${ }^{2}$ - Qiang (Ed) Zhang ${ }^{3} \cdot$ Rose Hamershock $^{3}$ - Jake E. Radell $\mathbb{I}^{4}$ • \\ Jun Yeop Lee ${ }^{4} \cdot$ Jasmine Tatum ${ }^{4} \cdot{\text { Albert } \mathrm{Y} . \mathrm{Wu}^{5}}^{5}$
}

Received: 21 October 2019 / Revised: 7 January 2020 / Accepted: 4 March 2020 / Published online: 29 April 2020

(c) The Author(s), under exclusive licence to The Royal College of Ophthalmologists 2020

\begin{abstract}
Background/objectives Patients with ophthalmic emergencies often present to emergency rooms. Emergency medicine (EM) physicians should feel comfortable encountering these conditions. We assessed EM physicians' comfort working up, diagnosing, and managing ophthalmic emergencies.

Subjects/methods $329 \mathrm{EM}$ physicians participated in this cross-sectional multicentre survey. Questions inquired about the amount, type, and self-perceived adequacy of ophthalmic training. Likert scales were used to assess confidence and comfort working up, diagnosing, and managing ophthalmic emergencies.

Results Participants recall receiving a median of 5 and $10 \mathrm{~h}$ of ophthalmic training in medical school and residency, respectively. Few feel this prepared them for residency $(16.5 \%)$ or practice $(52.0 \%)$. Only $50.6 \%$ feel confident with their ophthalmic exam. Most (75.0\%) feel confident in their ability to identify an ophthalmic emergency, but $58.8 \%$ feel well prepared to work them up. Responders feel more comfortable diagnosing acute retrobulbar hematoma (72.5\%), retinal detachment (69.8\%), and acute angle closure glaucoma (78.0\%) than central retinal artery occlusion (28.9\%) or giant cell arteritis (53.2\%). Only $60.2 \%$ feel comfortable determining if canthotomy and cantholysis is necessary in the setting of acute retrobulbar hematoma, and $40.3 \%$ feel comfortable performing the procedure. There was a trend towards attending physicians and providers in urban and academic settings feeling more comfortable diagnosing and managing ophthalmic emergencies compared to trainees, non-urban, and non-academic physicians.

Conclusions Many participants do not feel comfortable using ophthalmic equipment, performing an eye exam, making vision or potentially life-saving diagnoses, or performing vision-saving procedures, suggesting the need to increase ophthalmic training in EM curricula.
\end{abstract}

$\triangle$ Albert Y. Wu

awu1@stanford.edu

1 Department of Ophthalmology, Wills Eye Hospital, Philadelphia, PA 19107, USA

2 Department of Emergency Medicine, Brandon Regional Hospital, Brandon, FL 33511, USA

3 Biostatistics Consulting Core, Vickie and Jack Farber Vision Research Center, Wills Eye Hospital, Philadelphia, PA 19107, USA

4 Department of Medical Education, Icahn School of Medicine at Mount Sinai, New York, NY 10029, USA

5 Department of Ophthalmology, Stanford University School of Medicine, Palo Alto, CA 94305, USA

\section{Introduction}

Delayed care for ophthalmic emergencies can lead to irreversible vision loss or blindness [1-4], which decreases quality of life for patients and leads to significant personal and societal costs [5, 6]. Much of the responsibility to recognize the emergency and initiate prompt and appropriate care falls on emergency medicine (EM) physicians, as ocular complaints represent a substantial proportion of emergency department (ED) visits [7-12]. In the United States (US), from 2006 to 2011, 11,929,955 ED visits were for ophthalmic complaints, averaging nearly 2 million eyerelayed ED visits and costing approximately $\$ 2.0$ billion annually [10].

As EM physicians are often the first members of the healthcare system to encounter a patient with an ophthalmic 
emergency, it is important that EM physicians feel confident diagnosing and managing these cases. However, research outside of the US suggests that EM physicians may not be adequately trained in ophthalmology [13-18]. Prior research in the United Kingdom has demonstrated that the majority of senior house officers have "little or no confidence" in handling ophthalmic cases, and emergency departments there may be poorly equipped to manage ophthalmic emergencies [14-17]. In London, Ontario, Canada, EM physicians have been reported to have a diagnostic accuracy rate of only $39 \%$ for ophthalmic conditions [18]. As far as we are aware, no such similar research has been published in the United States.

The aim of this study is two-fold: to better understand how much ophthalmic training is incorporated into emergency medicine residencies across the US, and to assess how comfortable emergency physicians in the US feel managing emergent ophthalmic disease.

\section{Methods}

This study was determined by the Institutional Review Board (IRB) of Wills Eye Hospital to be IRB-exempt. A link to an anonymous and confidential survey hosted on a common online platform, Google Forms, was distributed by email to the Council of Emergency Medicine Residency Directors (CORD). CORD is composed of residents and educators in Emergency Medicine, including program directors, assistant program directors, clerkship directors, and departmental chairs. To increase participation, personalized emails containing the survey link were later sent to residency program directors or department chairs of 138 emergency departments across the US. The survey was then distributed to faculty and residents at their discretion. As there was significant overlap between recipients of this email and CORD membership, this served as a follow up notification for most recipients.

Survey questions assessing participant comfort level with certain situations or extent of agreement with particular statements were asked on a Likert scale from 1 to 5 , with 1 representing "very uncomfortable" or "strongly disagree" and 5 representing "very comfortable" or "strongly agree". In our results, we report the proportion of responders who answered 4 or 5 , indicating feeling comfortable (comfortable/very comfortable) or agreement (agree/strongly agree) with the statement in question.

\section{Statistical analysis}

Summary statistics are reported on a participant level. Comparisons between groups for categorical variables were tested with Chi-square test or Fisher's Exact test for categorical variables, depending on the expected cell count. Since the continuous variables were not normally distributed, differences between groups for these variables were tested with the rank sum test. A two-sided alpha level of 0.05 was used to determine significance. All $p$-values regarding the Likert scale data are for comparisons of the combined scales (i.e., very uncomfortable/comfortable, neutral, and comfortable/very comfortable) between groups. Summaries were computed using SAS 9.4.

\section{Results}

Table 1 summarizes basic demographic information about participants. In brief, the majority of responders were male $(59.8 \%, 196 / 328)$, trainees (residents or fellows) $(51.8 \%, 170 /$ $328)$, work primarily in an urban setting $(78.7 \%, 259 / 329)$,

Table 1 Participant demographics.

\begin{tabular}{lc}
\hline & No. $(\%)$ \\
\hline Male, $n=328$ & $196(59.8)$ \\
Level of training, $n=328$ & \\
Resident & $156(47.6)$ \\
Fellow & $14(4.3)$ \\
Attending & $158(48.2)$ \\
Location of training, $n=329$ & \\
Northeast USA & $141(42.9)$ \\
Southeast USA & $47(14.3)$ \\
Southwest USA & $20(6.1)$ \\
Midwest USA & $79(24.0)$ \\
West USA & $38(11.6)$ \\
Outside of the USA & $4(1.2)$ \\
Workplace geography, $n=329$ & \\
Urban & $259(78.7)$ \\
Suburban & $61(18.5)$ \\
Rural & $7(2.1)$ \\
Combination & $2(0.6)$ \\
Work setting, $n=329$ & \\
Academic medical centre & $59(37.8)$ \\
Community hospital & $44(28.2)$ \\
County hospital & $41(26.3)$ \\
Multiple settings & $12(7.7)$ \\
Years in practice (for attendings), $n=158$ & $256(77.8)$ \\
5 or less & $56(17.0)$ \\
$6-10$ & $6(1.8)$ \\
11-15 & \\
PG or more & \\
PGY-2 & \\
PGY-3 & \\
\hline
\end{tabular}


and work primarily in an academic medical centre $(77.8 \%$, 256/329).

Most responders report that training in diagnosis and management of ophthalmic disease was a formal part (including lectures, didactics, and skills sessions) of their medical school (78.6\%) and residency curricula $(94.8 \%)$. Participants recall receiving a median of 5 and $10 \mathrm{~h}$ of formal training in medical school and residency, respectively. Only $16.5 \%$ (54/327) feel that medical school prepared them well for encountering ophthalmic emergencies during residency, and just over half $(52.0 \%, 169 / 325)$ feel that their residency training is or was adequate for practice after residency. Accordingly, 70.9\% (231/326) and 75.1\% (247/329) wished they received more training in ophthalmic disease during medical school and residency, respectively.

Overall, 94.8\% (310/327) of responders have access to an on-call ophthalmologist in the setting in which they work. Most $(92.4 \%, 304 / 329)$ have access to a functional slit lamp, although $21.6 \%$ (71/328) have not had formal or dedicated teaching in how to use one and only $46.5 \%$ (153/ 329) feel comfortable/very comfortable using one. Fewer $(86.6 \%, 284 / 328)$ have access to a direct ophthalmoscope, and $34.7 \%(114 / 329)$ have not had formal or dedicated teaching in how to use one. Only $27.4 \%$ (90/328) feel comfortable/very comfortable using a direct ophthalmoscope. Almost all $(99.7 \%, 325 / 326)$ responders have access to a device to measure intraocular pressure, most commonly a Tonopen $(91.3 \%, 294 / 322)$, followed by an iCare rebound tonometer $(5.9 \%, 19 / 322)$. The remainder use a Schiotz tonometer, Goldmann applanation tonometry, finger tension, a combination of methods, or did not know.

Figure 1 summarizes participant responses to general questions regarding comfort identifying and workup up ophthalmic emergencies. In general, most responders $(84.4 \%)$ feel they know which eye diseases are emergent and which are not, and $75.0 \%$ feel confident in their ability to identify an ophthalmic emergency. Even so, only $58.8 \%$ feel wellprepared to work up patients with these emergencies, and $65.5 \%$ feel comfortable generating a differential diagnosis for ophthalmic emergencies. Approximately half (50.6\%) feel confident with their ophthalmic exam.

Figure 2 summarizes the proportion of responders who feel comfortable diagnosing patients with specific diseases: retinal detachment (RD), acute angle closure glaucoma (AACG), central retinal artery occlusion (CRAO), giant cell arteritis (GCA), and acute retrobulbar hematoma (ARBH). Most participants $(71.3 \%, 234 / 328)$ feel comfortable/very comfortable using ultrasound to evaluate the status (attached vs. detached) of the retina. Most $(72.5 \%)$ also feel comfortable diagnosing ARBH and determining (comfortable/very comfortable: $60.2 \%, 197 / 327$ ) if orbital decompression by lateral canthotomy and inferior cantholysis (LCC) is necessary in the setting of ARBH, but few feel comfortable (comfortable/very comfortable: $40.3 \%, 132 / 327)$ performing the procedure. Almost half $(44.0 \%, 144 / 327)$ have never performed one, and the same number have only performed 1 or 2 . The remainder have performed 3 to $5(9.8 \%, 32 / 327), 6$ to $9(1.2 \%, 4 / 327)$, or 10 or more $(0.9 \%, 3 / 327)$.

\section{Urban vs. non-urban (including suburban/rural/ hybrid $)(N=329)$}

Providers in urban settings were more often female $(43.4 \%$ vs. $28.6 \%, p=0.03$ ) and in a higher post-graduate year (for residents, $p=0.03$ ). The urban providers were more often also in academic settings $(88.0 \%$ vs. $40.0 \%, p<0.0001)$ with access to an on-call ophthalmologist (97.7\% vs. $84.3 \%, p<0.0001)$.

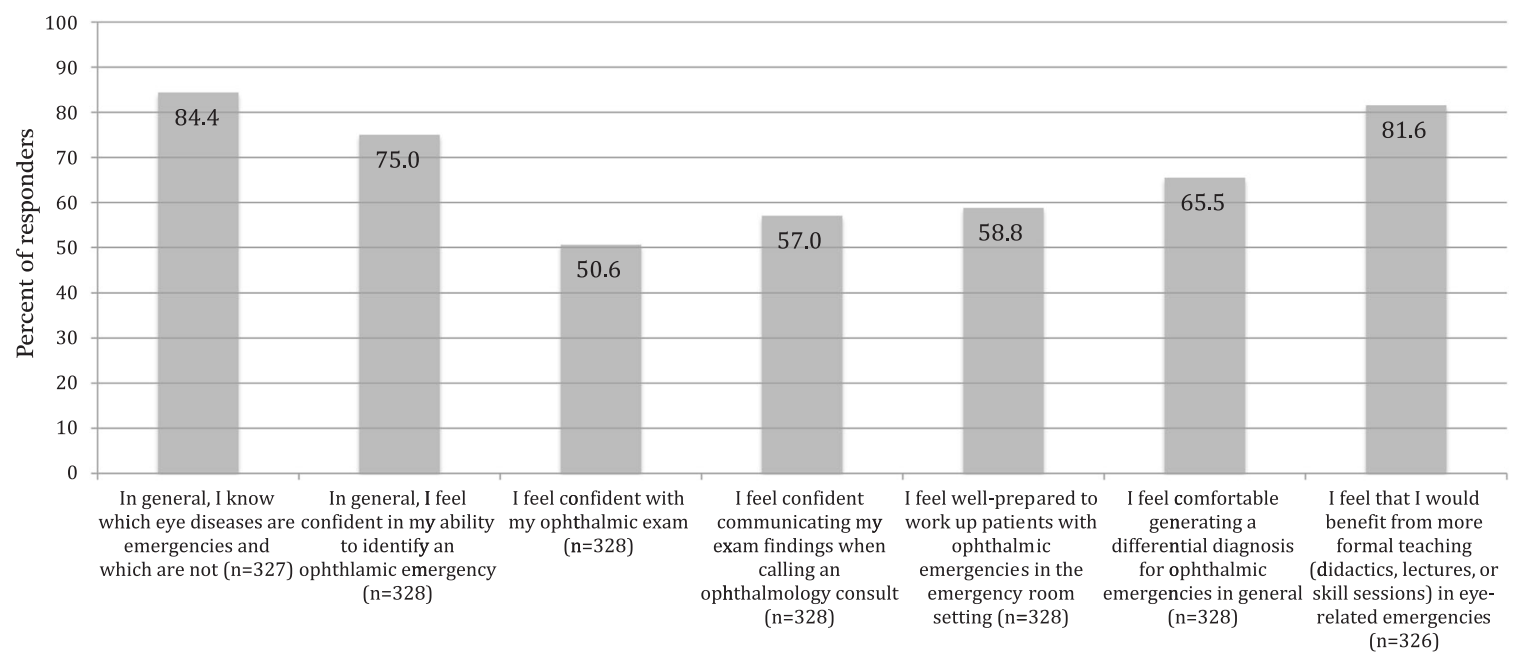

Fig. 1 EM physicians' responses to questions regarding comfort identifying and workup up ophthalmic emergencies. The graph demonstrates the percent of responders (vertical axis) indicating agreement/strong agreement with statements regarding identification and work up of ophthalmic emergencies (horizontal axis). 


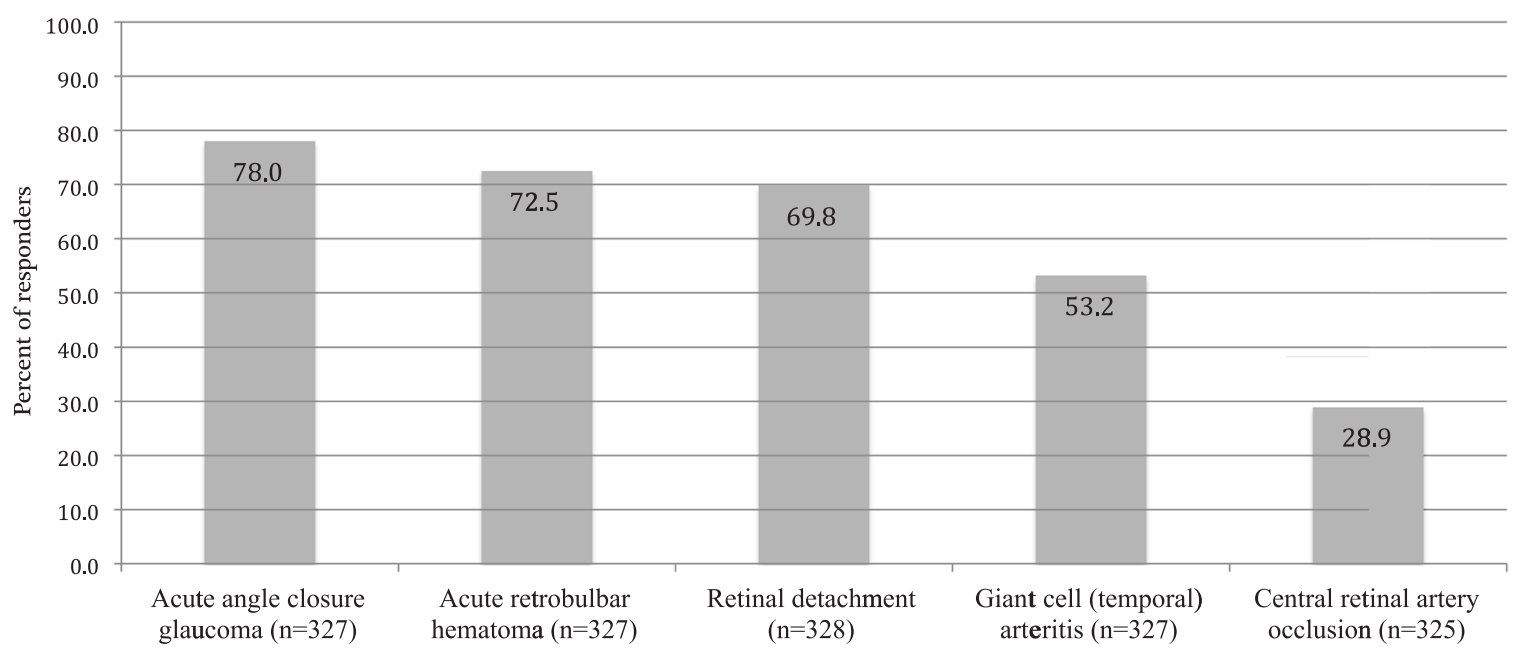

Fig. 2 EM physicians' comfort diagnosing ophthalmic emergencies. The graph demonstrates the percent of responders (vertical axis) who indicate feeling comfortable/very comfortable diagnosing specific ophthalmic emergencies (horizontal axis).

More urban providers reported having training in diagnosis and management of ophthalmic disease as part of their residency curriculum $(96.5 \%$ vs. $88.6 \%, p=0.01)$ and less wished they received more training in ophthalmic disease during medical school $(66.9 \%$ vs. $85.5 \%, p=0.003)$ and residency $(72.2 \%$ vs. $85.7 \%, p=0.02)$ compared to the non-urban group.

The urban group felt more confident than the non-urban group in their ability to identify an ophthalmic emergency (agree/strongly agree: $77.9 \%$ vs. $64.3 \%, p=0.007$ ) and communicate exam findings when calling an ophthalmology consult (agree/strongly agree: $60.9 \%$ vs. $42.9 \%, p=$ 0.03 ). They also felt more comfortable diagnosing patients with suspected ARBH (74.7\% vs. $64.3 \%, p=0.03)$. The urban and non-urban groups had a difference in proportion for comfortability diagnosing patients with suspected GCA, with more urban providers reporting neutral $(36.2 \%$ vs. $21.4 \%)$ and less reporting uncomfortable or very uncomfortable $(11.3 \%$ vs. $22.9 \%, p=0.01)$.

More urban providers felt comfortable determining if orbital decompression is necessary in the setting of ARBH (comfortable/very comfortable: $64.2 \%$ vs. $45.7 \%, p=0.003$ ). They also performed more ( $>2$ performed: $14.4 \%$ vs. $2.9 \%$, $p=0.008$ ) and felt more comfortable performing LCC (comfortable/very comfortable: $43.6 \%$ vs. $28.6 \%, p=0.001$ ).

All other survey responses were similar between urban and non-urban providers.

\section{Academic vs. non-academic (including community/ hybrid/county hospital) $(N=329)$}

The distribution of residency locations differed between providers in an academic vs. a non-academic setting, with almost half of the academic group being in the Northeast (46.9\%) compared to $28.8 \%$ of the non-academic group $(p=0.04)$. Providers practicing in an academic setting were also primarily in an urban setting (89.1\%) compared to $42.5 \%$ of providers in the non-academic group $(p<0.0001)$. The academic group reported having more access to an oncall ophthalmologist $(98.4 \%$ vs. $81.9 \%, p<0.0001)$. This group also feels more comfortable (comfortable/very comfortable: $49.2 \%$ vs. $37.0 \%, p=0.04$ ) using a slit lamp.

Non-academic providers wished they received more training in ophthalmic disease during medical school more often than academic providers did $(81.9 \%$ vs. $67.7 \%, p=$ 0.02 ), although both groups had an equal proportion of providers $(75.0 \%$ vs. $75.3 \%, p=1.0)$ wishing they received more training in ophthalmic disease during residency. The academic group felt more confident in their ability to identify an ophthalmic emergency (agree/strongly agree: $77.6 \%$ vs. $65.8 \%, p=0.05$ ) and communicate exam findings when calling an ophthalmology consult (agree/strongly agree: $60.8 \%$ vs. $43.8 \%, p=0.03$ ).

The academic group felt more comfortable determining if orbital decompression is necessary (comfortable/very comfortable: $65.4 \%$ vs. $42.5 \%, p=0.0003$ ) and more comfortable performing a LCC (comfortable/very comfortable: $44.5 \%$ vs. $26.0 \%, p=0.006$ ).

All other survey responses were similar between providers in an academic and non-academic setting.

\section{Attending physicians vs. trainees (including residents and fellows) $(N=328)$}

Attending physicians were less likely to wish they received more training in ophthalmic disease during medical school $(60.3 \%$ vs. $80.5 \%, p<0.0001)$ and residency $(65.8 \%$ vs. $83.5 \%, p=0.0003$ ), received more hours of formal ophthalmology training/teaching (median 10 vs. $8, p<0.0001$ ), and more often felt that this training was adequate for 
practice after residency $(61.4 \%$ vs. $43.4 \%, p=0.001)$. They also were less likely to feel more formal teaching in eyerelated emergencies would be beneficial (agree/strongly agree: $77.1 \%$ vs. $85.7 \%, p=0.009$ ).

Attendings more often had formal teaching or dedicated teaching time in how to use a slit lamp (89.9\% vs. $67.6 \%$, $p<0.0001)$ than residents and fellows and feel more comfortable using a slit lamp (comfortable/very comfortable: $63.3 \%$ vs. $31.2 \%, p<0.0001)$. They also had more formal teaching or dedicated teaching time in how to use a direct ophthalmoscope $(74.7 \%$ vs. $56.5 \%, p=0.0005)$ and feel more comfortable using a direct ophthalmoscope (comfortable/very comfortable: $40.1 \%$ vs. $15.9 \%, p<0.0001)$.

Attendings more often felt like they know which eye diseases are emergencies (agree/strongly agree: $93.7 \%$ vs. $75.6 \%, p<0.0001$ ), felt confident in their ability to identify an ophthalmic emergency (agree/strongly agree: $88.0 \%$ vs. $62.7 \%, p<0.0001$ ), felt well-prepared to work up patients with ophthalmic emergencies in the emergency room setting (agree/strongly agree: $77.2 \%$ vs. $42.0 \%, p<0.0001$ ), and felt comfortable generating a differential diagnosis for ophthalmic emergencies in general (agree/strongly agree: $81.6 \%$ vs. $50.3 \%, p<0.0001)$. They also felt more confident with their ophthalmic exam (agree/strongly agree: $67.1 \%$ vs. $34.9 \%$, $p<0.0001)$ and communicating their exam findings when calling an ophthalmology consult (agree/strongly agree: $75.9 \%$ vs. $39.6 \%, p<0.0001)$.

Trainees and attendings felt equally comfortable (72.2\% vs. $67.5, p=0.67$ ) diagnosing patients suspected of $\mathrm{RD}$, and more trainees felt comfortable using an ultrasound to evaluate the status of the retina $(79.9 \%$ vs. $62.0 \%, p=0.0002)$. However, attendings more often felt more comfortable than trainees diagnosing patients with other diseases, including AACG (comfortable/very comfortable: $87.9 \%$ vs. 68.6\%, $p<0.0001$ ), CRAO (42.3\% vs. $16.7 \%, p<0.0001)$, GCA (59.2\% vs. $47.3 \%, p=0.002)$, and $\mathrm{ARBH}(82.8 \%$ vs. $62.7 \%$, $p<0.0001)$.

Attendings more often felt comfortable determining if orbital decompression is necessary in the setting of ARBH (comfortable/very comfortable $67.5 \%$ vs. $53.3 \% p=0.004$ ) and performing a LCC $(51.0 \%$ vs. $30.8 \%, p=0.0008)$. Attendings performed more LCCs (performed $>2: 22.3 \%$ vs. $2.4 \%, p<0.0001)$.

All other survey responses were similar between attendings and residents/fellows.

\section{Discussion}

Since eye complaints are common in emergency departments across the United States [7-12], and since prompt and appropriate care is important for visual prognosis $[1-4,19]$, it is important that EM physicians are well prepared to encounter these cases. However, in this study, a substantial proportion of responders report not feeling comfortable using basic ophthalmic equipment, performing an eye exam, making vision or in some cases potentially life-saving diagnoses, or performing vision-saving procedures.

The vast majority of responders have access to basic ophthalmic equipment in their daily practice, including a slit lamp (92.4\%), direct ophthalmoscope (86.6\%), and device to measure intraocular pressure $(99.7 \%)$. This is superior to reported access in the UK, where a 1993 survey found that only $57.8 \%$ of accident and emergency (A\&E) departments (equivalent to an American ED) had a slit lamp, although this increased to $83.5 \%$ by $2003[15,16]$. Most $(78.4 \%)$ responders in this study report having had formal training on the slit lamp, but only $46.5 \%$ feel comfortable using one (compared to $68.4 \%$ who received training and $39.1 \%$ who felt comfortable in the UK) [16]. Even fewer (65.3\%) received formal training for the direct ophthalmoscope, which only $27.4 \%$ feel comfortable using. Since ophthalmic emergencies in the US often present to general emergency departments - in contrast to the UK, where many large hospitals have separate eye causality departments-it is particularly important for EM physicians in the US to have access to ophthalmic equipment for thorough ocular evaluation. However, these tools are difficult to use and their utility is limited by user proficiency. As most responders feel uncomfortable using these devices, it is perhaps unsurprising that only half $(50.6 \%)$ feel confident in their ophthalmic exam, implying a need for increased emphasis on equipment training during EM residency.

EM physicians indicated that they feel more comfortable diagnosing ARBH (72.5\%), RD (69.8\%), and AACG $(78.0 \%)$ than CRAO $(28.9 \%)$ or GCA $(53.2 \%)$. However, the latter two are particularly important diagnoses to be able to make, as both have features which may be more debilitating than ARBH, AACG, or RD in the absence of timely diagnosis.

ARBH and AACG quickly lead to vision loss or blindness in the affected eye when management is delayed [2022]. RD also leads to monocular vision loss, but optimal time to repair depends on multiple factors beyond our scope [23]. Unlike these usually unilaterally vision-impairing emergencies, delayed diagnosis and treatment of GCA may lead to rapid bilateral blindness [24-26]. Fortunately, GCA is uncommon; the estimated age-adjusted and sex-adjusted prevalence is 204 per 100,000 people aged $\geq 50$ in the US [27], $15 \%$ to $25 \%$ of which may develop permanent vision loss [28]. Even so, as vision loss may be preventable with early initiation of treatment, and since vision loss is associated with substantial personal and societal costs, early recognition is crucial.

In contrast, there is no evidence-based therapy available to reverse vision loss in CRAO [29]. Nevertheless, timely 
diagnosis is critical as CRAO has serious systemic health implications. There is increasing awareness in the medical community, including by the American Heart Association and American Stroke Association, that acute ischemic retinal cell death is a stroke equivalent [30]. As such, acute CRAO constitutes a medical emergency warranting immediate systemic work up [30]. Moreover, recent metaanalyses suggest that thrombolysis (intravenous or intraarterial) appears to be a promising therapy, although safety and efficacy data from randomized clinical trials are needed [31, 32]. If thrombolysis does become the standard of care, the window for administration will likely be a matter of hours [31], further heightening the need for rapid diagnosis in the ED.

Although EM physicians feel relatively comfortable diagnosing ARBH, a minority (40.3\%) feel comfortable/ very comfortable performing LCC, and almost half (44.0\%) have never performed LCC. Ocular trauma is the most common ophthalmic complaint encountered in the ED and the most common cause of unilateral vision loss worldwide $[7,8,33]$. The reported incidence of ARBH in the setting of ocular trauma varies but ranges from $<1 \%$ to $3.6 \%[33,34]$. Immediate orbital decompression, most commonly by LCC, is required to optimize visual potential in the setting of orbital compartment syndrome secondary to ARBH $[19,20,34,35]$. Since a strong correlation between preparedness for various procedural skills and confidence of EM physicians performing those procedures has been demonstrated [36], EM physicians should feel comfortable performing this vision-saving procedure.

In the United States, EM training includes a three or four year residency in emergency medicine following medical school graduation. Some physicians may choose to pursue further sub-specialization by completing a fellowship following residency (Fig. 3). In our analysis, we consider both residents and fellows to be trainees. Attending physicians (who have completed training) in general felt more comfortable diagnosing and managing ophthalmic emergencies than trainees (except for the use of ultrasound), which likely reflects cumulative experience and continued learning after residency. There was also a trend in our data towards urban and academic providers feeling more comfortable diagnosing and managing ophthalmic emergencies. As our data are skewed towards academic (78\% of responders) and urban (79\% of responders) providers, our results therefore likely overestimate EM physician comfort and confidence in the diagnosis and management of ophthalmic emergencies nationwide. Although is it a limitation to our study that our sample may not be representative of all EM physicians in the United States, this probable overestimation only further strengthens our conclusion that there is a need for increased ophthalmic training in EM residencies.

There are several other limitations to our study. First, we are unable to determine the response rate. As described, we emailed our survey link to emergency department administrators nationwide, but it was distributed at their discretion and we lack a mechanism by which to determine how many physicians received the link. Second, as we asked physicians to retrospectively estimate the amount of teaching received during various periods of training, some aspects of our results may be subject to recall biases. Finally, the relationship between confidence and competence is complex and not perfectly correlated [37]. Although it is desirable for physicians to feel confident and comfortable with the diseases they manage, high or low confidence may not always translate into good or bad clinical outcomes, respectively. We cannot determine from our data what proportion of ophthalmic emergencies are correctly diagnosed or managed in the ED setting. This might be an interesting topic for future research.

In summary, EM physicians surveyed report feeling inadequately prepared by their medical school and residency training to encounter ophthalmic emergencies. Concordantly,

\author{
Fig. 3 Medical education in the \\ United States. The figure \\ describes the process of \\ becoming a physician in the US, \\ including the general \\ educational steps required for all \\ physicians, as well as the sub- \\ specialty training requirements \\ for ophthalmologists and \\ emergency medicine physicians.
}

- Medical Education in the United States

- Physicians in the United States first earn an undergraduate university degree, followed by a medical degree (each typically consisting of 4 years of study)

- After earning a medical degree, physicians complete a residency (specialty training) in their desired field of medicine

- Upon completion of residency, physicians are expected to be able to practice in their field independently as an attending

- Residency requirements vary across programs and by specialty

- Ophthalmology Residency:

- 1 year of internship

- Rotations in internal medicine, general surgery, and various other specialties

- 3 years of ophthalmology-specific training

- Additional sub-specialty training is optional and may be pursued in a post-residency fellowship

- Emergency Medicine Residency:

- Most commonly 3 years, although some programs are 4 years

- Some programs offer combined training with other medical specialties (i.e., internal medicine or pediatrics)

- Additional sub-specialty training is optional and may be pursued in a post-residency fellowship 
most desire more training. Responders also report low levels of comfort in multiple areas: using basic ophthalmic equipment, performing an eye exam, making certain vision or potentially life-saving diagnoses, and performing visionsaving procedures. Taken together, these findings suggest the need to increase ophthalmic training in emergency medicine curricula. Considering that the majority of responders have on-call access to an affiliated ophthalmology department, and that most responders desire more ophthalmic training, increased educational collaboration between ophthalmology and emergency medicine departments may be one practical approach to accomplish this.

\section{Summary}

\section{What was known before}

- Timely treatment for these ophthalmic emergencies is important to ensure the best visual prognosis for patients. Since patients with eye emergencies often present to emergency rooms, emergency medicine physicians should feel comfortable encountering these cases in order to diagnose them and provide appropriate and prompt initial management.

- Prior studies have shown that emergency medicine physicians in the United Kingdom are underprepared to encounter eye emergencies. This has not been studies in the United States. Description of US Ophthalmic training: In the United States, ophthalmology training after medical school graduation consists of completing a four-year ophthalmology residency. Although there are variations across training programs, the first year of residency usually consists of predominantly general medicine or general surgery rotations. The following three years focus exclusively on ophthalmology. Upon completion of residency, trainees are prepared to practice comprehensive ophthalmology. Sub-specialty training (retina, oculoplastics, glaucoma, etc.) typically entails completion of an additional one or two-year fellowship program. Emergency medicine training in the United States consists of, depending on the specific program, a three or four-year emergency medicine residency.

\section{What this study adds}

- This is the first study to show that emergency medicine physicians in the United States report generally low levels of comfort using basic ophthalmic equipment; performing an eye exam; making vision saving or, in some cases, potentially life-saving diagnoses; and performing vision-saving procedures. These findings underscore the need to increase ophthalmic training in emergency medicine curricula in the United States.

Acknowledgements The authors acknowledge the support of the Biostatistics Consulting Core, Vickie and Jack Farber Vision Research Center, Wills Eye Hospital.

\section{Compliance with ethical standards}

Conflict of interest The authors declare that they have no conflict of interest.

Publisher's note Springer Nature remains neutral with regard to jurisdictional claims in published maps and institutional affiliations.

\section{References}

1. Kikushima W, Imai A, Hirano T, et al. Quick referral and urgent surgery to preempt foveal detachment in retinal detachment repair. Asia-Pac J Ophthalmol. 2014;3:141-5. https://doi.org/10.1097/ APO.0b013e3182a81240.

2. David R, Tessler Z, Yassur Y. Long-term outcome of primary acute angle-closure glaucoma. Br J Ophthalmol. 1985;69:261-2. https://doi.org/10.1136/bjo.69.4.261.

3. González-Gay MA, García-Porrúa C. Systemic vasculitis in adults in northwestern Spain, 1988-97. Clinical and epidemiologic aspects. Medicine. 1999;78:292-308. https://doi.org/10.1097/ 00005792-199909000-00002.

4. Hayreh SS. Ocular vascular occlusive disorders: natural history of visual outcome. Prog Retin Eye Res. 2014;41:1-25. https://doi. org/10.1016/j.preteyeres.2014.04.001.

5. Scott IU, Smiddy WE, Schiffman J, Feuer WJ, Pappas CJ. Quality of life of low-vision patients and the impact of low-vision services. Am J Ophthalmol. 1999;128:54-62. https://doi.org/10. 1016/s0002-9394(99)00108-7.

6. Köberlein J, Beifus K, Schaffert C, Finger RP. The economic burden of visual impairment and blindness: a systematic review. BMJ Open. 2013;3:e003471. https://doi.org/10.1136/bmjopen2013-003471.

7. Haring RS, Canner JK, Haider AH, Schneider EB. Ocular injury in the United States: emergency department visits from 2006-11. Injury. 2016;47:104-8. https://doi.org/10.1016/j.injury.2015.07.020.

8. Cheung CA, Rogers-Martel M, Golas L, Chepurny A, Martel JB, Martel JR. Hospital-based ocular emergencies: epidemiology, treatment, and visual outcomes. Am J Emerg Med. 2014;32: 221-4. https://doi.org/10.1016/j.ajem.2013.11.015.

9. Owens PL, Mutter R. Emergency Department Visits Related to Eye Injuries, 2008: Statistical Brief \#112. In: Healthcare Cost and Utilization Project (HCUP) Statistical Briefs. Rockville (MD): Agency for Healthcare Research and Quality (US); 2006.

10. Channa R, Zafar SN, Canner JK, Haring RS, Schneider EB, Friedman DS. Epidemiology of eye-related emergency department visits. JAMA Ophthalmol. 2016;134:312-9. https://doi.org/10. 1001/jamaophthalmol.2015.5778.

11. Washington RE, Andrews RM, Mutter R. Emergency Department Visits for Adults with Diabetes, 2010: Statistical Brief \#167. In: Healthcare Cost and Utilization Project (HCUP) Statistical Briefs. Rockville (MD): Agency for Healthcare Research and Quality (US); 2006.

12. Stagg BC, Shah MM, Talwar N, Padovani-Claudio DA, Woodward MA, Stein JD. Factors affecting visits to the emergency department 
for urgent and nonurgent ocular conditions. Ophthalmology. 2017; 124:720-9. https://doi.org/10.1016/j.ophtha.2016.12.039.

13. Saifuddin A, Brookes R Improving the management of patients with acute red eyes in a large London Emergency Department. BMJ Qual Improv Rep. 2014;3. https://doi.org/10.1136/bmjqua lity.u201656.w1962.

14. Ah-Kee EY, Scott RA, Shafi A, McCabe G, Lim LT. Are junior doctors in today's NHS competent in managing ophthalmic cases in the emergency department? Eye Lond Engl. 2016;30:164. https://doi.org/10.1038/eye.2015.193.

15. Tan MM, Driscoll PA, Marsden JE. Management of eye emergencies in the accident and emergency department by senior house officers: a national survey. J Accid Emerg Med. 1997;14:157-8. https://doi.org/10.1136/emj.14.3.157.

16. Sim D, Hussain A, Tebbal A, Daly S, Pringle E, Ionides A. National survey of the management of eye emergencies in the accident and emergency departments by senior house officers: 10 years on-has anything changed? Emerg Med J EMJ. 2008;25:76-77. https://doi. org/10.1136/emj.2007.049999.

17. Murray PI, Benjamin M, Oyede O. Can general A\&E doctors manage common eye emergencies? Eye Lond Engl. 2016;30: 1399-400. https://doi.org/10.1038/eye.2016.99.

18. Nari J, Allen LH, Bursztyn LLCD. Accuracy of referral diagnosis to an emergency eye clinic. Can J Ophthalmol. 2017;52:283-6. https://doi.org/10.1016/j.jcjo.2016.12.011.

19. Pamukcu C, Odabaşı M. [Acute retrobulbar haemorrhage: an ophthalmologic emergency for the emergency physician]. Ulus Travma Ve Acids Cerrahi Derg. 2015;21:309-14. https://doi.org/ 10.5505/tjtes.2015.16768.

20. Christie B, Block L, Ma Y, Wick A, Afifi A. Retrobulbar hematoma: a systematic review of factors related to outcomes. J Plast Reconstr Aesthetic Surg. 2018;71:155-61. https://doi.org/10. 1016/j.bjps.2017.10.025.

21. Zhang X, Liu Y, Wang W, et al. Why does acute primary angle closure happen? Potential risk factors for acute primary angle closure. Surv Ophthalmol. 2017;62:635-47. https://doi.org/10. 1016/j.survophthal.2017.04.002.

22. Pokhrel PK, Loftus SA. Ocular emergencies. Am Fam Physician. 2007;76:829-36.

23. Wykoff CC, Smiddy WE, Mathen T, Schwartz SG, Flynn HW, Shi W. Fovea-sparing retinal detachments: time to surgery and visual outcomes. Am J Ophthalmol. 2010;150:205-10.e2. https://doi.org/10.1016/j.ajo.2010.03.002.

24. Albarrak AM, Mohammad Y, Hussain S, Husain S, Muayqil T. Simultaneous bilateral posterior ischemic optic neuropathy secondary to giant cell arteritis: a case presentation and review of the literature. BMC Ophthalmol. 2018;18:317. https://doi.org/10. 1186/s12886-018-0994-9.

25. De Smit E, O'Sullivan E, Mackey DA, Hewitt AW. Giant cell arteritis: ophthalmic manifestations of a systemic disease. Graefes Arch Clin Exp Ophthalmol. 2016;254:2291-306. https://doi.org/ 10.1007/s00417-016-3434-7.

26. Hayreh SS, Podhajsky PA, Zimmerman B. Ocular manifestations of giant cell arteritis. Am J Ophthalmol. 1998;125:509-20.

27. Crowson CS, Matteson EL. Contemporary prevalence estimates for giant cell arteritis and polymyalgia rheumatica, 2015. Semin Arthritis Rheum. 2017;47:253-6. https://doi.org/10.1016/j.sema rthrit.2017.04.001.

28. Baig IF, Pascoe AR, Kini A, Lee AG. Giant cell arteritis: early diagnosis is key. Eye Brain. 2019;11:1-12. https://doi.org/10. 2147/EB.S170388.

29. Chronopoulos A, Schutz JS Central retinal artery occlusion-a new, provisional treatment approach. Surv Ophthalmol. 2019. https://doi.org/10.1016/j.survophthal.2019.01.011.

30. Biousse V, Nahab F, Newman NJ. Management of acute retinal ischemia: follow the guidelines! Ophthalmology. 2018;125: 1597-607. https://doi.org/10.1016/j.ophtha.2018.03.054.

31. Dumitrascu OM, Shen JF, Kurli M, et al. Is intravenous thrombolysis safe and effective in central retinal artery occlusion? A critically appraised topic. Neurologist. 2017;22:153-6. https://doi. org/10.1097/NRL.0000000000000129.

32. Page PS, Khattar NK, White AC, et al. Intra-arterial thrombolysis for acute central retinal artery occlusion: a systematic review and meta-analysis. Front Neurol. 2018;9:76. https://doi.org/10.3389/ fneur.2018.00076.

33. Romaniuk VM. Ocular trauma and other catastrophes. Emerg Med Clin North Am. 2013;31:399-411. https://doi.org/10.1016/j.emc. 2013.02.003.

34. Fattahi T, Brewer K, Retana A, Ogledzki M. Incidence of retrobulbar hemorrhage in the emergency department. J Oral Maxillofac Surg. 2014;72:2500-2. https://doi.org/10.1016/j.joms.2014.06.457.

35. Lima V, Burt B, Leibovitch I, Prabhakaran V, Goldberg RA, Selva D. Orbital compartment syndrome: the ophthalmic surgical emergency. Surv Ophthalmol. 2009;54:441-9. https://doi.org/10. 1016/j.survophthal.2009.04.005.

36. Druck J, Valley MA, Lowenstein SR. Procedural skills training during emergency medicine residency: are we teaching the right things? West J Emerg Med. 2009;10:152-6.

37. Roland D, Matheson D, Coats T, Martin G. A qualitative study of self-evaluation of junior doctor performance: is perceived "safeness" a more useful metric than confidence and competence? BMJ Open. 2015;5:e08521. https://doi.org/10.1136/bmjopen-2015-008521. 